\title{
Educação: nova fronteira da bioética
}

\author{
Education: new frontier of bioethics
}

Jansen Ribeiro Pires ${ }^{1}$ Volnei Garrafa ${ }^{1}$
${ }^{1}$ CátedraUNESCO de Bioética. Núcleo de Estudos e Pesquisas em Bioética. Programa de PósGraduação em Bioética. Campus Universitário Darcy Ribeiro, Asa N orte. 70919-970 Brasília DF. bioetica@unb.br
Abstract This study analyses the opinion of teachers regarding the inclusion of contents on Bioethics in the curricular structure of high school. Six schools were selected: three public and three privatein the main administrativeregion of Brasília. In a universe of 340 teachers, 150 joined the research. They were given a questionnaire with answers about the existence or not of curricular contents related to the construction of values in the students. The second phase counted with 140 teachers out of those who joined the first part of the research. These teachers received a text bri efly explaining what Bioethi cs is with a closed space for answering if the inclusion of a new discipline on Bioethics would help creating values and ethics attitudes in the students. There was space for justifying this answer. Data analysis showed that: (a) the school has not carried out its role as an instrument of a critical vision; (b) according to the teachers, this is the result of the absence of a discipline focused on the approach to ethic questions; (c) $51 \%$ of the respondents took sides with the inclusion of a discipline that deals with Bioethics in the curricular structure of high school because they believe that it would help the construction of the students' moral values and affirmative attitudes.

Key words High school, Values and attitudes, Educational structure, Curricular contents, Bioethics
Resumo Este estudo analisa a opinião de professores quanto à introdução de conteúdo sobre bioética no currículo do ensino médio. Foram selecionadas seis escolas: três públicas e três particulares da principal região administrativa de Brasília. De um universo de 340 professores, 150 aderiram à pesquisa. Foi apresentado um questionário com alternativas versando sobrea existência ou não de conteúdo relacionado com a construção de valores nos estudantes. 0 segundo momento contou com 140 dos professores que participaram da primeira fase. Foi-Ihes entregue um texto queresumia o que era a bioética. Ao final, havia um espaço à pergunta se uma nova disciplina de bioética preencheria a lacuna curricular na formação de valores e atitudes éticas nos estudantes. A análise dos dados demonstrou que: (a) a escola não tem cumprido a função de instrumentar a formação da consciência ética; (b) na opinião dos docentes, isto vem acontecendo em razão da inexistência de uma disciplina que se responsabilize pela abordagem destas questões; (c) $51 \%$ dos entrevistados se posicionaram a favor da introdução de uma disciplina que trate da bioética na estrutura curricular do ensino médio, por acreditarem queela poderia contribuir à construção de valores morais e atitudes afirmativas dos estudantes.

Palavras-chave Ensino médio, Valores e atitudes, Estrutura educacional, Conteúdo curricular, Bioética 


\section{Introdução}

Segundo Paulo Freire', a formação da consciência ética não pode ser vista como algo que ocorra espontaneamente. Estacapacidadedependedos estímulos promovidos pela família e pel os instrumentos de inserção social, em particular a escola. Não sepodem exigir comportamentos éticos se não forem ofertadas oportunidades para sua construção e realização. A retomada e a valorização de temas da esfera da ética ajudam a definir o padrão comportamental das pessoas. Por essa razão, é conveniente recordar alguns trechos mais significativos da história e que impactaram a humanidade no último século, já que muitas vezes tais ocorrências foram negligenciadas no sistema educacional, não permitindo uma abordagem crítica dos grandes temas que fragilizaram boa parcela da população mundial. Se estivermos deacordo com Singer $^{2}$ que se posiciona a favor da obrigação que têm os ricos deajudar os mais pobres, éindispensável compreender os fatos que seguem.

A partir da segunda metade do século XX, a humanidade deu um salto científico-tecnológico sem precedentes, possibilitando o controle mais adequado de doen ças, o incremento da produção de alimentos eo aumento da expectativa e qualidade de vida das pessoas ${ }^{3}$. No entanto, todo esse progresso não se refletiu numa melhora significativa na vida da maioria da população mundi$\mathrm{al}^{4}$. Muito pelo contrário, os $20 \%$ da população mais rica do planeta usufruem hoje de nada menos que $82,7 \%$ de toda a riqueza mundial, sendo que os $20 \%$ mais pobres contam com apenas $1,4 \%{ }^{5}$. Persistem, portanto, os mesmos problemas do passado, tais como a exclusão social, a desigualdade entre homens emulheres, a eutanásia com seus conflitos sobrea autonomia ${ }^{6}$, o aborto, as questões relacionadas aos direitos políticos e civis, a fragilidade da democracia, etc. Os desequilíbrios provocados pela má distribuição das riquezas e dos benefícios tecnológicos acabaram fazendo com que os países pobres e em desenvolvimento ajudassem a financiar, unilateral e paradoxalmente, o bem-estar das nações desenvolvidas, sem que ocorresse a devida reciprocidade.

No início deste século XXI, além dos problemas citados, vislumbra-se um quadro de distorções muito mais complexo, proveniente do refinamento tecnocientífico no campo biomédico e em outras áreas, como engenharia genética, biologia molecular que está relacionada ao mapeamento do genoma humano, a manipulação genética sob as perspectivas e promessas da tecnologia de clonagem ${ }^{7}$, as terapias envolvendo o uso de células-tronco, os transplantes de órgãos e tecidos, a saúde reprodutiva quanto à justa alocação de recursos ${ }^{8}$, a preservação do meio ambiente, o uso da energia nuclear, entre outros. Além disso, o tempo natural para o amadurecimento de posturas que se adequassem aos problemas tradicionais, que já era escasso, tornou-se ainda menor, subtraindo da humanidade o período mínimo necessário de reflexão ética para lidar com tais demandas. Por essas e outras razões, tornou-se imperativo que se procurasse pensar num espaço que discutisse e avaliasse, com maior objetividade e rapidez, tanto os dilemas morais antigos como os mais recentes. É nesse contexto que surgiu, então, a ética aplicada e, dentre seus desdobramentos, a bioética9.

Um dos marcos referenciais do surgimento desta disciplina remonta à publicação do livro Bioethics: a bridge to the future, em 1971, que alertava sobre a fragilidade dos ecossistemas e a precariedade da vida humana. Rapidamente, os pesquisadores do Instituto Kennedy passaram a fazer uso da palavra bioética para tratar de reflexões decunho ético no campo biomédico, quanto aos dilemas que envolvem o nascimento, 0 transcurso e a morte dos seres humanos. $\mathrm{Na}$ atualidade, após aprovação da Declaração Universal sobre Bioética e Direitos Humanos da Unesco, em outubro de 2005, o campo de influência da bioética perpassa praticamente todas as áreas da academia, inserindo-se no contexto internacional como referencial teórico queinstiga à análise e discussão de dilemas morais de amplo espectro, atuando com uma pauta de atividades bastante diversificada. Como não poderia deixar de ser, ela emerge também no panorama educacional, contribuindo para a compreensão dos problemaséticoshistoricamente persistentes, que ainda não foram solucionados, e emergentes, que fazem parte dos novos desafios do século XXI.

\section{Marco conceitual}

O marco teórico destetrabalho fundamentou-se em três vertentes. A primeira, conforme explica M orin ${ }^{10}$, destaca que a escola não poderia ficar al heia aos fatos da vida (as relações interpessoais), hipertrofiando as competências técnicas em detrimento de algo mais sublime, a formação ética. Na visão do autor, o tecnicismo exacerbado limita os horizontes e diminui os predicados da cidadania, gerando incapacidades para refletir mais cuidadosamente sobre qualquer assunto que fuja da especialidade enfocada. 
O paradigma da complexidade advoga que as instituições de ensino deveriam proporcionar uma educação que favorecesse a construção global do conhecimento ${ }^{11}$, contrariando o modelo positivista de fragmentação dos saberes. Para M orin, a instauração da ciência moderna, ocorrida há um pouco mais de três séculos, embora tivesse possibilitado avanços científico-tecnológicossignificativos, acabou tornando muito mais difícil o exercício de organizar e refletir sobre as informações transmitidas pelas diversas disciplinas. Trata-se do mal da hiperespecialização, no qual o próprio especialista torna-se ignorante de tudo aquilo quenão concerne a sua disciplina eo não especialista acaba renunciando prematuramente a toda possibilidade de refletir sobre 0 mundo, a vida e a sociedade.

Este fenômeno agudizou-se ainda mais devido à tendência atual deseconsiderar quea modalidade de conhecimento mais capaz de responder aos anseios sociais seja essencialmente a científi$\mathrm{ca}^{11,12}$. Isto pode ser verdade em determinados aspectos, uma vez que não há como negar que a ciência possibilitou uma série deavanços em praticamente todas as áreas do conhecimento humano. No entanto, no que se refere às reflexões filosóficas sobre valores e atitudes éticas, os cientistas tornaram-se demasiadamente frágeis ${ }^{11}$. Desta forma, em geral, encontram-se desprovidos dos meios conceituais e detempo para refletir mais comedidamente sobre os impactos que suas atividades podem trazer para as sociedades e os ecossistemas. Os senhores da ciência não conseguem fazer com que seus blocos unidisciplinares dialoguem com os aspectossociais, culturais, econômicos e ambientais nos quais estão inseridos.

Esta trajetória em direção à fragmentação e à disjunção dos saberes impede o desenvolvimento de uma sensibilidade mais acurada por meio das relações transdiciplinares. Cria-se, então, a necessidade de religar os conhecimentos, a partir do reconhecimento da complexidade como instrumento de cumprimento desta tarefa ${ }^{11}$. Segundo Hawking ${ }^{13}$, a constatação empírica de que o universo não funciona respeitando cegamente as leis deterministas, conforme tinha defendido, no início do século XIX, o cientista francês $M$ arquês de Laplace, estimula a busca de novas abordagens da realidade, como, por exemplo, as reflexões bioéticas.

Embora fixações deterministas, separatistas, reducionistas e logicistas tenham sido questionadas ao longo do século XX, isto não foi suficiente para que ocorresse uma reforma si gnificativa na forma de estruturação do pensamento ${ }^{14}$.
Na verdade, o paradigma da ordem, da organização e da fragmentação do conhecimento, que permeia o racionalismo determinista, infelizmente continua valendo einfluenciando as atuaispráticas educacionais.

Este problema levantado pela complexidade ainda é um pensamento marginal, pouco difundido no meio científico, filosófico e educacional, mas quetem amplas possibilidades de fazer prosperar a reforma dos saberes humanos ${ }^{11}$. Tal iniciativa pode ser percebida no pensamento de Potter ${ }^{15}$, ao defender que os estudos relativos aos dilemas morais deveriam iniciar desde cedo, já que os jovens ainda não estão totalmente amarrados ao determinismo, viabilizando o resgate do elemento humano, que se contrapõe ao individualismo racionalista que obscurece os conflitos sociais. É retomada, assim, a urgência de se contextualizar os saberes às necessidades socioculturais da atualidade, além de observá-las de uma forma mais multi, inter e transdisciplinar, além de integrada ${ }^{16}$.

Toda esta linha de pensamento possibilita que seponha em discussão a perspectiva bioética, que se preocupa em refletir sobre os limites da moralidade provenientes tanto do sofisticado poder técnico, derivado da hiperespecialização, quanto das mazelas cotidianas que prejudicam os países mais pobres do planeta. Para Morin ${ }^{14}$, não se está querendo com isto invadir as competências restritas a cada área disciplinar. 0 que se analisa, segundo o autor, é que, para a maioria dos especialistas, ninguém, além deles mesmos, é capaz derefletir sobre o quefazem. Evoca-se, dessa forma, a necessidade de questionar se devem ser os cientistas os únicos e legítimos detentores do poder de decisão quanto aos rumos efinalidades de seus trabalhos. Evidenciando este posicionamento, o estudioso exemplifica que as grandes descobertas sobre a natureza da matéria, do tempo e do espaço, realizadas por Einstein, Planck, Bohr e Heisenberg, foram colocadas em debate para o público não especializado, que mesmo não detendo competências técnicas para discussões decunho teórico, produziu intervenções queversavam a respeito do caráter ético das pesquisas. Logo, torna-se válida a idéia de se discutir, também no ambiente escolar, temas afetos aos grandes problemas levantados pela bioética.

É finalidade da escola intervir para a construção de uma consciência ética que ultrapasse as fronteiras nacionais, transformando o educando em cidadão ${ }^{17}$. Um mundo em crescente globalização, que ainda não conseguiu resolver seus problemas cotidianos e persistentes e que agora se 
encontra atropelado por outros emergentes e de fronteiras do saber, necessita promover a reforma do conhecimento. Esta reorientação podecontribuir para a busca da humanização e pacificação das relações humanas, estimulando a reconciliação do homem com a natureza.

No entendimento de Potter ${ }^{15}$, solidário com as observações supracitadas, os estudantes deveriam ter contato, desde cedo, com reflexões filosóficas da ética. $\mathrm{Na}$ visão do pesquisador, eles ainda não estariam encapsulados pelo determinismo laplaciano, facilitando a construção da sensibilidade ética ainda em tenra idade. Tudo isso proporcionaria a assimilação de elementos argumentativos que se contrapõem ao individualismo racionalista, que obscurece os conflitos sociais e os problemas ambientais. A percepção dequeeleégente, pertencente a uma determinada condição social, impregnado de crenças, valores e significados, se encaixaria na proposição de Engelhardt ${ }^{18}$, de que a diversidade moral é real. 0 reconhecimento da complexidade da realidade como um fato concreto facilitaria o enfrentamento do cotidiano trágico no qual a humanidade está imersa, como os problemas do crescimento das desigualdades sociais, que alimenta o terrorismo, a ameaça termonuclear e, talvez, a mais terrível tragédia provocada pela intervenção humana: a degradação ambiental que põe em risco a manutenção da própria espécie.

Para continuar aprofundando sobre a necessidade de se construir uma visão mais ampla sobre o estudo da ética, fez-se imperativa no delineamento do referencial teórico da presentepesquisa a utilização de uma linguagem bioética que proponha o uso de ações afirmativas capazes de modificar a realidade trágica em que vivem as populações pobres dos países periféricos.

N este sentido, a segunda vertente teórica que será tomada como referência de estudo será a chamada bioética deintervenção, a qual vem sendo construída na Universidade de Brasília desde 1998, e que busca relacionar a disciplina com as distorções sociais, econômicas, educacionais ede saúde pública pelas quais passam as nações periféricas do mundo, em especial as da América Latina. Questões como a pobreza, a má distribuição de renda, os critérios para a justa alocação de recursos e o atual modelo de globalização, que aumenta a distância entre países ricos e pobres, têm sido enfaticamente criticadas por essa corrente crítica da bioética ${ }^{19}$.

Conforme explicam seus defensores, existem boas razões para advogar que um novo enfoque bioético, baseado em práticas intervencionistas, públicas e diretas, poderia contribuir para a diminuição das inequidades. 0 pressuposto central desta visão é de que as políticas de saúdee as políticas de cunho social deveriam atender ao maior número de pessoas, pelo maior tempo possível, trazendo os melhores resultados ${ }^{19}$. Esse posicionamento confronta com algumas tradicionais concepções bioéticas que privilegiam os interesses individuais de conotação anglo-saxônica, que procuram impor determinados padrões morais, dos países centrais, descontextualizados da realidade dos países periféricos ${ }^{20}$, em detrimento daqueles quedizem respeito às necessidades das massas, as quais são invariavelmenteformadas por pessoas excluídas e pobres.

A preferência da bioética de intervenção em focar seus esforços no estudo dos problemas persistentes da bioética vem no sentido de apresentar propostas efetivas que façam valer a voz e os direitos das populações marginalizadas. No seu escopo, destacam-se as reflexões a respeito da pobreza, da exclusão educacional, das dificuldades de acesso aos serviços de saúde, do abandono institucional associado à excessiva concentração de renda e de restrições das liberdades individuais, que caracterizam a estratificação social dos países periféricos.

Para alguns autores, seria interessanteincluir tais fatos no âmbito da formação educacional média, para que sejam discutidos e avaliados os problemas que estão mais próximos dos estudantes quevivem naAmérica Latina ${ }^{21}$. N esse sentido, as escolas deveriam abrir espaços para que se exercitasse uma cuidadosa reflexão, já que a rapidez com que as informações circulam é impeditiva de uma análise minuciosa destes problemas, transformando-os apenas em mais um dado a ser politicamente eclipsado.

0 perigo da descontextualização política da bioética estáno fato dela ser uma disciplina excessivamente acadêmica, servindo muitas vezes como ferramenta de justificação teórica neutral frente aos desastres econômicos, sociais e educacionais em que se encontram as nações periféri$\operatorname{cas}^{19}$. É fundamental quese recuperea capacidade de indignação para que, a partir desse sentimento, atitudes concretas no combate às desigual dades possam ser tomadas, evitando a atenção exclusiva e teórica direcionada aos problemas urgentes do dia a dia ${ }^{19}$. Surge, daí, o princípio de proteção que prescreve que, a bem da dignidade, se tomem atitudes que diminuam o sofrimento dos mais frágeis. N este sentido, Schramm ${ }^{22}$ argumenta que a chamada bioética de proteção fundamenta atitudes de Estado que garantem condi- 
ções objetivas e subjetivas para proporcionar, minimamente, uma vida decente às pessoas. Esta argumentação se coloca como condição necessária para que mecanismos de intervenção possam ser legitimamente utilizados, uma vez que disponibiliza fundamentação de caráter técnico, operacional e conceitual à bioética deintervenção, para que esta, por sua vez, possa reivindicar, investida de autoridade teórica/moral, a politização dos eixos temáticos da bioética, num contexto mais macro, atuando ideologicamente no processo de empoderamento dos vulnerados ${ }^{23}$.

Observa-se, assim, uma sinergia e complementaridade entre estas duas propostas conceituais - bioética de proteção ebioética deintervenção - uma vez que ambas se dedicam a objetivos semelhantes, ou seja, de se colocar como ferramentas de evocação de responsabilidadeem defesa dos mais vulnerávei ${ }^{23,24}$. A inserção do estudo da ética no campo educacional é uma das recomendações da bioética de intervenção, uma vez que as desigualdades sociais fragilizam as noções de cidadania, dificultando ou mesmo impedindo a tomada de decisões conscientes e autônomas ${ }^{19}$. Para seus defensores, o mundo encontra-se dividido entre dois grupos humanos: um, bem desenvolvido, com cidadãos privilegiados/incluídos, no qual suas necessidades básicas já foram satisfatoriamente resolvidas. E o outro, com cidadãos desprivilegiados/excluídos, cujas pendências encontram-se ainda muito atrasadas e em aberto. Tais fatos proporcionam contemplar a idéia de que a escola deveria, também, dedicar-se aos estudos e análises das reflexões éticas a respeito dos graves problemas sociais em que vivem as nações periféricas, objetivando, por meio dela, o empowerment das pessoas despossuídas, que é o processo de resistir de maneira criteriosa e bem fundamentada a todas aquelas instâncias de poder estabelecidas numa ordem social que se dedica a impor sentidos sociais discriminatórios ${ }^{25}$. Todo este pensamento está de acordo com a pedagogia libertadora idealizada por Paulo Freire ${ }^{26}$, que enxerga 0 estudante como agente atuante no processo construtivo de sua identidade de cidadão crítico eesclarecido.

Ademais, a proposta de uma bioética engajada com os problemas sociais não significa adotar uma postura paternalista, uma vez que, ao fundamentar-se no princípio de proteção pela legitimidades de suas ações, a autonomia deverá ajustar-se às necessidades do bem comum para construção de uma sociedade que privilegie posturas éticas ${ }^{24}$. Neste sentido, um dos desafios apresentados à bioética deintervenção eà bioéti- ca de proteção é atuar no campo da educação para listar os dilemas morais, discuti-los e me diá-los, no intuito de fazer germinar a idéia de justiça social, não só como um direito de todos, mas também como obrigação de cada um, resgatando o significado real da palavra equidade, proporcionando maior lucidez coletiva para que se atinja a desejável iluminação moral.

Para completar o ciclo de fundamentação teórica da presente pesquisa, uma tercei ra vertente teórica er eferencial do presenteestudo foi tomada a partir das concepções de Amartya Sen, ganhador do Prêmio Nobel de Economia de 1998. 0 autor enfoca suas análises na problemática do desenvolvimento humano e na eliminação da pobreza por meio da expansão das liberdades coletivas e individuais capazes de minimizar os desequilíbrios provocados pelo empobrecimento. Nada menos que duas terças partes da população mundial não tiveram acesso aos bens mais básicos oriundos do progresso tecnológico-científico produzidos no planeta no século passa$\mathrm{do}^{27}$. Este fenômeno é analisado por Sen sob a perspectiva da valorização das liberdades coletivas e individuais ${ }^{28}$.

$\mathrm{N}$ a sua argumentação, a educação, dentre outras liberdades, seria um dos mecanismos que viabilizaria a inclusão das pessoas pela via das oportunidades econômicas e da participação política. Ao apontá-la como um dos fatores importantes para atingir este objetivo, o pesquisador busca resgatar seu papel como elemento ativo e crítico nesse processo. Para ele, a liberdade precede e antecede qualquer menção que se faça quanto ao desenvolvimento: não existe desenvolvimento sem liberdade, nem liberdade sem desenvolvimento. Assim, para que se torne possível superar a fome, a pobreza, as ameaças de destruição do meio ambiente e outras formas de iniquidades, exigir-se-á da sociedade uma postura de cumplicidade fortalecedora da idéia de liberdade, da qual ela mesma não pode se furtar.

Este é o principal argumento levantado por Sen ao conceber o desenvolvimento como expansão das liberdades em todas as dimensões ${ }^{28} . \mathrm{Na}$ sua visão, as diversas instituições, em especial a escola, deveriam partir para a discussão dos problemas econômicos, sociais e políticos, a fim de criar uma educação ética reflexiva, o que, por sua vez, deslocaria os estudantes da posição de recebedores passivos de benefícios, para agentes ativos de mudanças. A partir desteposicionamento, ele procura demonstrar queo sucesso econômico não dependeexclusivamente do aumento do Produto Nacional Bruto e da renda de cada pessoa. 
Em seu livro Desenvolvimento como liberdade, defendeque outras variáveis, como os serviços de saúde, respeito aos direitos políticos/civis ea educação, fazem parte de um conjunto de oportunidades que determinam o progresso econômico de um país e de seus respectivos cidadãos.

Trata-se, portanto, de uma proposta centrada no conceito de liberdade. Por essa abordagem, a expansão da liberdade é tomada como principal fim eprincipal meio do desenvolvimento, pois busca, pela participação, transformar o indivíduo em um agenteativo, produtivo ecapaz de interagir socialmente com os outros membros de sua comunidade, por meio da livre escoIha e das oportunidades sociais. Estes são os prérequisitos essenciais e necessários para que haja desenvolvimento humano. Corroborando com este mesmo posicionamento, Labeyrie ${ }^{29}$ afirma que, desde 0 século XIX, o algoritmo econômico positivista vem se impondo no quadro mundial, sob a filosofia de explorar ilimitadamente os escassos recursos disponíveis no planeta, objetivando apenas a maximização dos lucros, sem considerar nuanças éticas e ambientais.

Labeyrie ${ }^{29}$ denuncia a falácia desse modelo, destacando que os benefícios provenientes das conquistas tecnológicas e 0 aumento das riquezas não necessariamente reverteram em proficiência para a parcela mais pobre da população mundial, já que não existem mecanismos de distribuição automática de riqueza para os excluídos. Sinaliza, ainda, que os critérios de inclusão dessas pessoas passariam necessariamente pelo acesso à saúde, à educação, às oportunidades de emprego, etc. Além disso, destaca que o desenvolvimento econômico não é sinônimo de progresso sociocultural; é, também, inexato imaginar que a ciência conduza necessariamente a um desenvolvimento. Torna-se urgente, portanto, minimizar todos os diversos fatores diminuidores das liberdades para garantir acesso aos bens e serviços, a fim de criar um ambiente propício para a realização da cidadania. $\mathrm{Na}$ abordagem do autor, a escola, mais uma vez, destaca-secomo elemento fundamental para a solução destes problemas, por meio de uma educação fundamentada em atitudes que valorizem a emancipação.

A partir do marco teórico aqui explicitado, 0 objetivo do presente estudo foi verificar junto a professores de escolas públicas e privadas de ensino médio, da cidade de Brasília (DF), a opinião sobre a inclusão de conteúdo programático de bioética na estrutura curricular secundária, no sentido de estimular oportuna e precocemente a construção de valores morais nos estudantes.

\section{M étodo}

Trata-se de uma pesquisa realizada na cidade de Brasília (DF), mais precisamente nas regiões conhecidas como Plano Piloto, (Asas N orte e Sul). 0 recorte do estudo consistiu na seleção de três escolas de cada segmento, dentre as seis públicas e onze particulares do ensino médio regular, que tivessem no mínimo quatrocentos alunos naárea geográfica estabelecida. A escolha foi aleatória, obedecendo ao descrito por Rosenthal ${ }^{30} \mathrm{e} \mathrm{Gi}{ }^{31}$. Foi atribuído um número para cada escola, se parando-as em duas categorias: escolas públicas e escolas particulares do ensino médio regular de Brasília/Plano Piloto/Asas Norte e Sul. Depois, todo esse material foi misturado numa pequena urna edevidamentesorteado, obedecendo-seaos critérios supracitados.

Como o objetivo da pesquisa versava sobre a opinião dos professores, verificou-se que era necessário estabelecer critérios de inclusão e exclusão dos docentes. Logo, só poderiam participar da pesquisa aqueles que atuassem diretamente na sala de aula como professores-regentes, ministrando al guma disciplina prevista na estrutura curricular. Por outro lado, seriam excluídos da amostra os professores com contratos especiais, cuja incerteza quanto a sua permanência nas instituições viesse a prejudicar 0 andamento da pesquisa. Isto se fez imperativo uma vez queo projeto foi delineado para ser executado em dois momentos distintos.

No primeiro momento, foi apresentado aos professores um questionário dentro de um envelope, contendo oito perguntas relacionadas com os objetivos gerais e específicos do estudo, as quais continham respostas fechadas em alternativas. 0 entrevistado poderia marcar com um " $x$ " a opção quelhe conviesse. $M$ as, para não cair na superficialidade das abordagens meramente quantitativas, como salientado por M inayo ${ }^{12}$, foram incorporadas às questões 2, 4, 5, 6 e 7 espaço suficiente para que 0 sujeito da pesquisa pudesse discorrer livremente sobre o que Ihe foi perguntando, permitindo, assim, a validação dos dados brutos por uma abordagem qualitativa.

No segundo momento da pesquisa, foram selecionados somente os professores que participaram da fase inicial. Foi-Ihes entregue um pequeno texto especialmente elaborado para essa finalidade, devidamente acondicionado em envelope, que explicava resumidamente o que é a bioética; ao final, havia um espaço fechado para resposta (sim ou não) à pergunta se uma nova disciplina de bioética na estrutura curricular da 
escola preencheria o espaço educacional na formação de valores eatitudes éticas nos estudantes e outro, aberto, para justificação da resposta do entrevistado.

Todos os participantes da pesquisa responderam voluntariamente aos questionários, manifestando sua disposição por meio da assinatura do termo deconsentimento livree esclarecido, incluído no envelope do primeiro questionário. 0 projeto de pesquisa foi submetido à aprovação prévia do Comitê de Ética em Pesquisa da Faculdade de Saúde da Universidade de Braślia.

\section{Resultados ediscussão}

Para que a presente discussão seja mais didática, a argumentação será desenvolvida respeitandose a ordem cronológica da pesquisa, iniciando pela análise das respostas do primeiro questionário e, em seguida, do segundo.

Participaram na primeira fase do estudo 150 professores, de um total de 340 possíveis, ou seja, $44 \%$ do universo estudado. Na segundafase, aceitaram participar da pesquisa 140 professores, ou seja, $41 \%$ do universo total dos docentes da amostra.

Na primeira pergunta, foi abordado como se posicionavam os estudantes quando colocados para discutir temas relacionados a dilemas morais que exigiam reflexão sobrevalores éticos. Os resultados apontaram para a carência deum exercício reflexivo na opinião de $61 \%$ dos entrevistados, ou seja, mais da metade dos docentes acreditavam numa atitude precipitada, inabilidade ou, ainda, na simples falta de interesse dos discentes frente a estes debates. U ma das razões desse comportamento pode ser imputada à falta de hábito de refletir eticamente, já que a formação de uma consciência ética e crítica não pode ser vista como algo que ocorra espontaneamente. Uma outra explicação viável refere-se à indiferença. A partir dessa atitude, é possível inferir que tal comportamento pode estar relacionado à fragmentação dos saberes, impossibilitando uma abordagem multidisciplinar e coerente dos acontecimentos. Os estudantes, neste caso, bem poderiam estar aptos a dar respostas técnicas, por exemplo, a partir de seus conhecimentos e habilidades mentais, mas inseguros a respeito de suas certezas morais.

A segunda pergunta procurou avaliar se temas relacionados à formação de valores e atitudes estão sendo suficientemente abordados pelas disciplinas quefazem parte da estrutura curricular. As opiniões ficaram bastante divididas, com
$57 \%$ dos professores equilibrando-se na resposta "mais ou menos". A discussão destes assuntos estaria parcialmente imersa nos componentes curriculares, sendo tratadastangencialmente, sem maiores compromissos com seu aprofundamento. Com relação aos demais sujeitos da amostra, $24 \%$ responderam que sim, $18 \%$, que não e $1 \%$ alegaram não saber se posicionar. Estes números demonstraram as ambiguidades existentes no trato do currículo ${ }^{11}$, resultado que vem ao encontro dos dados obtidos na primeira questão, que indicaram uma certa paralisia com relação às observações feitas pelos professores quanto ao comportamento de seus alunos por ocasião de discussões que exigissem deles (alunos) posições éticas conscientes.

$N$ as questões 3 e 4 , foi apresentada aos professores uma lista contendo vinte sugestões de tópicos gerais relacionados à ética/bioética que poderiam ser discutidos no ensino médio. Estes deveriam marcar apenas cinco opções em ordem de importância, numerando de 1 (a mais importante) a 5 (menos importante) aquelas que poderiam contribuir para uma melhor reflexão sobre os dilemas morais vividos na atualidade. A tabulação indicou a preferência dos entrevistados quanto ao eixo temático na seguinte ordem: 1ㅇ) valores e atitudes: $49 \%$; 2o) família: $45 \%$; 3o) direitoshumanos: $44 \%$; 40) ética: 40\%; e5o) qualidade da vida humana: $35 \%$. Observa-se, na listagem proporcionada pelas respostas, a prevalência de assuntos voltados a reflexões quefazem parte da vida cotidiana.

$\mathrm{Na}$ percepção de $\mathrm{Anjos}^{32}$, algo importante a ser recordado é que a presente pesquisa foi realizada tomando por amostragem professores residentes num país em desenvolvimento, cujo acesso da maioria da população aos serviços básicos de assistência à saúde, educação, segurança, entre tantos outros, estaria prejudicado. Consequentemente, estariam expostos a situações de vulnerabilidade, conforme definição dada por Kottow ${ }^{33}$. A parentemente, a seleção das categorias supracitadas parece estar ajustada a alguns dos principais debates da bioética na atualidade. As demais opções proporcionadas pelo questionário foram: avanços científicos e tecnológicos, desigual dades entre homens e mulheres, discriminação, drogas, exclusão social, meio ambiente, morte, políticas públicas, relacionamento, religião, saúde, sexualidade, trabalho, violência e vulnerabilidade.

$\mathrm{Na}$ questão 5 , os professores foram inquiridos se acreditavam que, além dos conhecimentos técnicos específicos das disciplinas, as escolas deveriam também seresponsabilizar pela forma- 
ção de valores e atitudes junto aos alunos. Nada menos que $63 \%$ dos entrevistados acham que a escola tem responsabilidade na formação de valores e atitudes, 30\% acham que a escola é parcialmente responsável por este quesito, apenas $1 \%$ se manifestaram negativamente e $6 \%$ se abstiveram de responder. Assim, já era de se esperar que as respostas à questão 6 , que procurava saber se os professores achavam que a inclusão de um novo conteúdo disciplinar na estrutura curricular poderia proporcionar uma visão mais crítica na construção de valores humanos no sentido de consolidar as atitudes éticas dos estudantes, contaria com significativo apoio dos entrevistados. Os índices obtidos na referida questão foram os seguintes: $50 \%$ dos entrevistados apoiaram a inserção denovo conteúdo disciplinar, 15\% optaram parcialmente pela inclusão de novos tópicos na estrutura, $22 \%$ repudiaram a proposta, $8 \%$ não souberam responder e $5 \%$ preferiram não opinar, revelando um panorama geral coerente com as informações obtidas pelas quatro perguntas anteriores.

Os resultados acima estão de acordo com as explicações de $M$ artinazzo ${ }^{34}$, que afirma que 0 compromisso de educar para a vida deve estar vinculado à escola, a qual deve dar especial atenção para o espaço de construção dos valores comunitários, fragilizados pelo crescente processo de globalização, no sentido de humanizar as relações interpessoais. Tal fato pode ser confirmado pela análise dos comentários dos docentes, que não vêem a escola somente como uma instituição de ensino reprodutora de conteúdo, que prepararia os alunos apenas para passar nos vestibulares. Morin ${ }^{35}$ fala que 0 excessivo peso do currículo está inviabilizando as oportunidades deseaprender, já que o enfoque incide em vencer maratonas de testes para ascensão aos cursos superiores, esquecendo queo conhecimento também deve ser útil para compreender o mundo e resolver problemas. Por este motivo, pode ser lido nos resultados das questões 0 interesse de expressiva porcentagem dos entrevistados deque se intervenha na estrutura curricular para que os estabelecimentos de ensino possam cumprir seu papel de estimular nos discentes a formação de consciência ética dotada de uma ação participativa comunitária, como defendido por Benatar ${ }^{36}$. Portanto, a necessidade de proporcionar aos estudantes uma maior "iluminação moral"3 urge por atitudes institucionais autorizadas, não apenas pelos mecanismos legais intrínsecos às funções da escola, mas predominantemente sobre a necessidade dese proteger os discentes da incons- ciência de seu estado. De acordo com as respostas dadas à questão 1 , vale a pena reforçar, os professores entrevistados consideraram os estudantes mal preparados para discutir temas relacionados a dilemas morais que exijam deles uma reflexão acerca de valores éticos .

A questão 7 procurou investigar quais outras instituições poderiam, além das escolas, se engajar na missão de proporcionar uma visão mais crítica na construção de valores e atitudes dos estudantes. As respostas apontaram um variado número de organizações, legalmente institucionalizadas no seio das sociedades, que levariam ao cumprimento desta mesma tarefa. Alguns participantes da pesquisa, ao preencherem os campos abertos proporcionados por algumas perguntas do questionário, chamaram a atenção para o fato da sociedade colocar excessivo peso sobre os ombros dos professores, que são os agentes diretos desta realização, justificando a necessidade de compartilhar essas atribuições com outros atores além, naturalmente, da família. Isso, no entanto, não foi considerado como argumento para escamotear suas responsabilidades de educadores; ao contrário, observou-se, nos resultados da questão 6 , como já foi mencionado, a concordância de quase dois terços dos respondentes (65\%) em colocar a escola como uma das aglutinadoras deste desafio.

Uma visão panorâmica dos resultados obtidos com a aplicação do questionário encontra fundamentação nas afirmações de Potter ${ }^{15}$, que apontava, já em 1970, não somente os problemas e aflições de um planeta devastado pelas ações humanas que punham em risco sua própria sobrevivência, mas os caminhos para seevitar o término da civilização. 0 autor sinalizava que só 0 envolvimento de toda a sociedade, incluindo aí 0 universo das instituições, poderia interromper a trajetória rumo à aniquilação. Esse pensamento, que revolucionou a forma pela qual expressiva parte da academia passou a ver o mundo, possibilitou que o conjunto das sociedades passasse a cobrar o cumprimento de determinados protocolos de transparência e eticidade quanto ao respeito à própria dignidade e futuro da vida humana.

$\mathrm{Na}$ última questão, de número 8 , procurouse investigar os limites das ênfases dadas aos aspectos formativos/criativos e informativos $\mathrm{da}$ educação. Os índices obtidos revelaram que 16\% das escolas onde os entrevistados trabal havam dariam maior importância aos aspectos formativos e criativos, proporcionando o desenvolvimento de uma consciência mais ética e crítica do mundo; $29 \%$ salientaram os aspectos informati- 
vos como seu principal foco, por se preocuparem predominantemente com a capacitação intelectual dos alunos para terem êxito nas provas e vestibulares; $45 \%$ indicaram que os dois pontos anteriores estavam sendo contemplados satisfatoriamentenas suas escolas; 8\% não responderam e $2 \%$ criaram outras alternativas para a indagação proposta.

Um balanço geral da pesquisa na sua parte inicial (primeiro momento) explica a própriaineficácia dos atuais currículos de estudo brasileiros para criar nos estudantes uma consciência ética, conforme aferido na questão 2, na qual os docentes consideraram queas disciplinas do ensino médio não têm contemplado suficientemente a discussão de temas relacionados à formação de valores e atitudes. Isso pode ser confirmado pela opinião somatória de $75 \%$ dos professores entrevistados, que consideraram que 0 atual modelo que forma o conjunto dos componentes curriculares trabalhados neste segmento tem dado pouca ou nenhuma importância aos temas relacionados à formação de valores e atitudes. Esta situação pode justificar, também, o motivo pelo qual $61 \%$ dos docentes participantes da pesquisa consideraram que os estudantes estão mal preparados para discutir dilemas morais que exijam deles uma reflexão acerca de valores éticos. Esse fenômeno, certamente, está ligado ao paradigma determinista que há muito tempo tem dificultado e limitado as abordagens dos saberes em sua complexidade, devido à fragmentação destes em microuniversos fechados, ocasionados pela superespecializações disciplinares. Tudo isso levar a crer que tanto os professores quanto as instituições de ensino médio estudadas, embora percebam o afastamento dos conteúdos ministrados no cotidiano aos estudantes, não têm conseguido cumprir com a obrigação de desenvolver uma autonomia comunitária participativa, ligada às responsabilidades sociais, de acordo com as declinações de Potter ${ }^{15}$.

No segundo momento da pesquisa, os docentes receberam outro envelope contendo um pequeno texto que definia, resumidamente, a bioética. Para que pudessem responder à pergunta ali inserida, foi solicitado que fizessem a leitura prévia do texto pois, ao final, havia um espaço fechado para resposta (sim ou não) à pergunta se uma nova disciplina de bioética na estrutura educacional da escola preencheria o espaço curricular na formação de valores e atitudes éticas nos estudantes, e outro aberto, para justificação da resposta. Os resultados indicaram a concordância de $51 \%$ dos entrevistados com a propos- ta, $48 \%$ não apoiariam e 1\% optou por não responder a questão. Estes números de certo modo reforçam a tendência apontada na questão 6 do questionário da primeira fase da pesquisa. Ali, $50 \%$ dos entrevistados sustentavam que a escola, mediante a inclusão denovo conteú do e estrutura disciplinar relacionados à bioética, poderia proporcionar uma visão mais crítica na construção de valores humanos. Embora a pesquisa não seja de modo algum conclusiva, pôde-se de preender de seus resultados a grande preocupação de expressivo número de professores entrevistados com a necessidade de fazer germinar a consciência ética dos estudantes, com valorização de temas relacionados à educação mais humanística, voltada para a análise desituações que fazem parte do cotidiano dos estudantes, tornando-os mais autônomos e solidários. Temas que, como se sabe, fazem parte do universo e das responsabilidades da bioética.

\section{Considerações finais}

Na presente pesquisa, ficou evidenciado que expressivo número de professores que atuam no ensino médio regular de escolas públicas e particulares da cidade de Brasília (DF), mais precisamente no Plano Piloto - Asas N orte e Sul -, são favoráveis à criação de uma nova disciplina ou espaço curricular que contemple as discussões propostas pela bioética. Esta opinião se refletena vontade de $50 \%$ dos entrevistados, contra apenas $22 \%$ que são contrários. Além disso, $51 \%$ do total dos entrevistados da amostra apontaram a bioética, especificamente, como a disciplina que deveria ser incluída na estrutura curricular para preencher a lacuna programática detectada. Um número significativo dosentrevistados referiu que a atual estrutura e contexto curricular não conseguem trabalhar, suficientemente, nas salas de aulas, temas que possibilitem a formação de valores e atitudes mais humanos e solidários nos estudantes. Dessa forma, o estudo de tópicos relativos a dilemas morais que exijam uma reflexão mais acurada desses parece vir ao encontro das necessidades, ou até mesmo do compromisso que a escola tem de promover uma educação mais ética e reflexiva.

Um dos pontos de maior relevância deste estudo incidiu justamente na pergunta 3 do primeiro questionário. Foram apresentados aos professores vinte tópicos gerais para que escoIhessem os cinco mais importantes, que poderiam contribuir para uma melhor reflexão sobre 
os dilemas morais vividos na atualidade. Destacaram-se: valores e atitudes; família; direitos humanos; ética e qualidade da vida humana, como sendo os temas que poderiam contribuir para a construção de uma proposta curricular que viesse estimular uma melhor reflexão sobre os dilemas morais. A escolha desses assuntos também permitiu verificar que os professores estão mais preocupados em analisar, junto com os alunos, os acontecimentos que fazem parte do dia a dia, isto é, aquelas questões que estão no campo das situações persistentes da bioética, revelando uma tendência decompromisso - independentemente de setratar de escola pública ou particular - frente aos problemas cotidianos geralmente decorrentes dos desequilíbrios sociais que tornam o país tão desigual.

As informações obtidas neste estudo dão suporte para a elaboração de uma proposta de inserção curricular sobre conteúdo bioético para o ensino médio regular, que potencialmentepoderia estimular nos estudantes a construção de atitudes mais éticas e comprometidas com a realidade. A escola ideal izada pelos professores entre- vistados, além de preparar os jovens para passar nos exames vestibulares, devetambém se responsabilizar pela formação de cidadãos compromissados com os interesses sociais. Esta proposição é compartilhada pela bioética de intervenção e pela bioética de proteção, quetambém advogam a necessidade de promoção de ações afirmativas diante das iniquidades pelas quais passam as populações pobres dos países periféricos ${ }^{19,23}$.

De acordo com as informações obtidas na presente pesquisa e com as propostas conceituais apresentadas, os educadores estão conscientes da necessidade de empoderar seus alunos, para que estes possam usufruir, no futuro, das liberdades proporcionadas por uma educação voltada para a discussão dos temas concretos do cotidiano. Acredita-se que isto viria aumentar a capacidade dos discentes de escolher conscientemente o que é melhor para si, para suas vidas e para a vida de suas comunidades. Os professores entrevistados mostraram-se preocupados em proporcionar, a partir da escola, o desenvolvimento de uma consciência ética cidadã nos seus estudantes.

\section{Colaboradores}

JR Pires participou de todas fases de elaboração da pesquisa e redação do artigo. V Garrafa orientou todo o processo de pesquisa. 


\section{Referências}

1. Freire P. Pedagogia da esperança: um reencontro com a pedagogia do oprimido. 11a ed. Rio de Janeiro: Paz e Terra; 2003.

2. Singer P. Ética prática. 3ạ ed. São Paulo: Martins Fontes; 2002.

3. Garrafa V. Bioética e manipulação da vida. In: Novaes $A$, organizador. 0 homem máquina. São PauIo: Companhia das Letras; 2003. p. 213-225.

4. Garrafa V, Costa SIF, Oselka G. A bioética no sécuIo XXI. In: Garrafa V, Costa SIF, organizadores. A bioética no século XXI. Brasília: Editora UnB; 2000. p. 13-24.

5. Berlinguer $\mathrm{G}$. A ciência e a ética da responsabilidade. In: Novaes A, organizador. 0 homem máquina. São Paulo: Companhia das Letras; 2003. p. 191-212.

6. Siqueira-Batista R, Schramm, FR. A eutanásia e os paradoxos da autonomia. Cien Saude Colet 2008; 13(1):207-221.

7. Aleksandrowicz AMC, Schramm, FR. Origem e destino revisitados: a clonagem entre a profecia e a promessa. Hist. cienc. saude- $M$ anguinhos 2007; 14(2):421-441.

8. Ribeiro CDM, Schramm, FR. Atenção médica, transplante de órgão e tecidos e políticas de focalização. Cad Saude Publica 2006; 22(9):1945-1953.

9. Costa SIF, Garrafa V, Oselka G. Apresentando a Bioética. In: Costa SIF, Garrafa V, Oselka G, organizadores. Iniciação à bioética. Brasília: Conselho Federal de Medicina; 1998. p. 15-18.

10. M orin E. Os sete saberes necessários à educação do futuro. Brasília: Cortez; 2000.

11. Morin E. Ciência com consciência. Rio de Janeiro: Bertrand Brasil; 2002.

12. M inayo MCS. 0 desafio do conhecimento: pesquisa qualitativa em saúde. 6a ed. Rio de Janeiro: Abrasco; 1999.

13. Hawking S. Breve história do tempo. Lisboa: Gradiva; 2004.

14. Morin E. 0 método 3: a consciência da consciência. Porto Alegre: Sulina; 2002.

15. Potter VR. Bridge to the future. N ew Jersey: Englerwod Clifts/Prentice-Hall; 1971.

16. Garrafa V. Multi-inter-transdisplinaridade, complexidade e totalidade concreta em bioética. In: Garrafa V, Kottow M, Saada A, organizadores. Bases conceituais da bioética: conceito latino-americano. São Paulo: Gaia; 2006. p. 93-119.

17. Morin E. A religação dos saberes: 0 desafio do século XXI. Rio de Janeiro: Bertrand Brasil; 2002.

18. Engelhardt HT. Fundamentos da bioética. São PauIo: Loyola; 1998.

19. Garrafa V, Porto D. Intervention bioethics: a proposal for peripheral countries in a context of power and injustice. Bioethics 2003; 17(5-6):399-416.

20. Garrafa V, Lorenzo C. Moral imperialism and multi-centric clinical trials in peripheral coutries. Cad Saude Publica 2008; 24(10):2219-2226.
21. Garrafa V. Bioética, saúde e cidadania. 0 M undo da Saúde 1999; 23(5):263-269.

22. Schramm FR. Proteger os vulnerados e não intervir aonde não se deve. Revista Brasileira de Bioética 2007; 3(3):379-391.

23. Schramm FR, Garrafa V. Diálogos [entrevista]. Série: Reflexões sobre a vida. Brasília: UnBtv; 2008.

24. Schramm FR, Kottow M. Princípios bioéticos em salud pública: limitaciones y propuestas. Cad Saude Publica 2001; 17(4):949-956.

25. Rajagopalan, K. Teorizando a resistência. In: Silva DEG, Vieira J, organizadores. Análise de discurso: percursos teóricos e metodológicos. Brasília: Plano; 2002.

26. Freire P. Pedagogia da autonomia: saberes necessários à prática educativa. São Paulo: Paz e Terra; 2005.

27. Garrafa V, Prado M M. Hard bioethics: demanding the best for the most. Perpectives in health 2002; 7(1):30-31.

28. Sen AK. Desenvolvimento como liberdade. São PauIo: Companhia das Letras; 2000.

29. Labeyrie V. As consequências ecológicas das atividades tecno-industriais. In: Morin $E$, organizador. A religação dos saberes: 0 desafio do século XXI. Rio de Janeiro: Bertrand Brasil; 2002. p. 126- 139.

30. Rosenthal R. Advanced social psychology. Georgia: University of Georgia Athens; 1995.

31. Gil AC. Como elaborar projetos de pesquisa. São PauIo: Atlas; 2002.

32. Anjos M F. Bioética em perspectiva de libertação. In: Garrafa V, Pessini L, organizadores. Bioética: poder e injustiça. São Paulo: Loyola; 2003. p.455-465.

33. Kottow MH. Comentários sobre bioética vulnerabilidade e proteção. In: Garrafa V, Pessini L, organizadores. Bioética: poder e injustiça. São Paulo: Loyola; 2003. p.71-78.

34. Martinazzo CJ. A utopia de Edgar M orin: da complexidade à cidadania planetária. Rio Grande do Sul: Unijui; 2002.

35. M orin $\mathrm{E}$. Os sete saberes necessários à educação do futuro. Brasília: Cortez; 2000.

36. Benatar SR. Bioética: poder e injustiça. In: Garrafa $V$, Pessini L, organizadores. Bioética: poder e injustiça. São Paulo: Loyola; 2003. p. 25-33.

Artigo apresentado em: 18/04/2008

Aprovado em 31/10/2008

Versão final apresentada em 29/11/2008 